\title{
Development of A Tool to Assess Resident Physicians' Perceived Competence for Patient-centered Obesity Counseling
}

\author{
Amy M. Burton ${ }^{1}$, Carl M. Brezausek ${ }^{2}$, Peter S. Hendricks ${ }^{3}$, April A. Agne ${ }^{4}$, Shirley L. Hankins ${ }^{5}$, Andrea L. Cherrington ${ }^{4}$ \\ ${ }^{1}$ Pediatric Endocrinology of North Texas, PLLC, Denton, TX, USA \\ ${ }^{2}$ Department of Education, University of Alabama at Birmingham, Birmingham, Alabama, USA \\ ${ }^{3}$ Department of Health Behavior, University of Alabama at Birmingham, Birmingham, AL, USA \\ ${ }^{4}$ Department of Medicine, Division of Preventive Medicine, University of Alabama at Birmingham, Birmingham, \\ Alabama, USA \\ ${ }^{5}$ Department of Pediatrics, University of Alabama at Birmingham, University of Alabama at Birmingham, Birmingham, \\ Alabama, USA \\ Correspondence: Andrea L. Cherrington, MD, MPH; $17202^{\text {nd }}$ Ave. South, MT 612, Birmingham, AL 35205, USA
}

Received: March 9, 2015 Accepted: March 23, $2015 \quad$ Online Published: May 19, 2015

doi:10.11114/jets.v3i4.707 URL: http://dx.doi.org/10.11114/jets.v3i4.707

\begin{abstract}
Physicians report a number of barriers to obesity counseling, among them low perceived competence in the ability to counsel. While there is increasing recognition of the need for resident training on counseling, implementation requires residency programs to have the necessary curricula and tools to evaluate training effectiveness. This study's objective was to describe the development and psychometric testing of the Perceived Competence for Obesity Counseling (PCOC) scale. Items were generated based on constructs from the $5 \mathrm{~A}$ 's counseling framework, review of the obesity literature, and expert opinion. The 20-item scale was piloted among 74 resident physicians. Exploratory factor analysis was conducted to identify the number and nature of factors in the scale. Pearson's correlation was used to assess scale validity of the total scores and sub-scale scores association with residents' overall confidence in counseling and outcome expectancy for obesity counseling. Analyses suggested a 3-factor solution. After the removal of cross loading items, eighteen items were retained; eleven items loaded on the first factor, four items on the second factor, and three on the third factor. Cronbach's alpha for the 18 -item PCOC scale was 0.95 indicating internal consistency. The PCOC scale was significantly correlated with resident's overall confidence in counseling $(r=0.60, p<0.01)$ and outcome expectancy for obesity counseling $(r=0.41, \mathrm{p}<0.01)$. This pilot study suggests PCOC is holds promise as a valid and reliable measure of resident's perceived competence for obesity counseling. Future studies are needed to assess the scale's association with counseling skills.
\end{abstract}

Keywords: obesity counseling, physician/patient relationship, clinical education, curriculum development/evaluation

\section{Introduction}

\subsection{Problem}

Over the last several decades, obesity has become a global epidemic, touching nearly every country in the world (Swinburn et al., 2011). In the United States, one third of the adult population is obese (Flegal, Carroll, Ogden, \& Curtin, 2010), placing a substantial burden on the health care system (Colditz, Willett, Rotnitzky, \& Manson, 1995; Walker et al., 1996). Behavior counseling is associated with a 5-10\% weight loss (McTigue et al., 2003), which significantly lowers the risk of progression to obesity-related illness (Goldstein, 1992; Sherwin et al., 2004). Physician counseling has the potential to effect meaningful change, particularly at the individual level, however, only a minority of physicians provide obesity counseling to their patients (Huang et al., 2004; Loureiro \& Nayga, 2006; Stafford, Farhat, Misra, \& Schoenfeld, 2000). Physicians report a number of barriers to obesity counseling, among them lack of knowledge and low perceived competence in their skills (Forman-Hoffman, Little, \& Wahls, 2006; Jay et al., 2008; Kushner, 1995). Indeed, physicians with lower confidence in their ability to counsel are less likely to provide obesity counseling (Perrin et al., 2008). Consequently, programs aimed at improving physicians' counseling skills and perceived competence for obesity counseling are needed, as are the necessary tools for evaluating such programs. Currently, there are no validated 
measurement tools to assess physicians' perceived competence for obesity counseling.

Strong frameworks for patient-centered obesity counseling are available but are rarely taught to physicians-in-training. Patient-centered counseling facilitates change by assessing patient needs and subsequently tailoring the intervention to the patient's readiness to change, personal goals, and unique challenges (Rosal et al., 2001) The 5 A's, Assessing obesity risk and motivation to change; Advising lifestyle change; Agreeing with the patient on collaboratively set goals; Assisting in addressing barriers and resources; and Arranging for follow-up (Jay et al., 2008; Jay, Gillespie, Schlair, Sherman, \& Kalet, 2010; Serdula, Khan, \& Dietz, 2003) have been endorsed by the U.S. Preventive Services task Force as a framework for behavior change counseling in the clinical setting (Whitlock, Orleans, Pender, \& Allan, 2002)

\subsection{Need for Resident Training in Patient-centered Counseling}

Physician training programs are keenly aware of the need for an increased focus on resident counseling skills. Recently, the Accreditation Council for Graduate Medical Education (ACGME) incorporated core competencies of "patient care" and "interpersonal and communication skills" in an effort to emphasize the importance of a patient-centered approach to counseling (Accreditation Council for Graduate Medical Education, 2007). In order to meet this requirement, residency programs must not only develop the necessary curricula, but will also need tools to evaluate training effectiveness. Typically, evaluation of resident counseling skills is done by direct observation of actual patient encounters or using standardized patients. External evaluation is less subject to bias and typically serves as the reference standard in studies examining the accuracy of self-assessment (D. A. Davis et al., 2006). However, these methods can be both labor intensive and challenging to implement (Glasgow, Emont, \& Miller, 2006). Self-assessment is an alternative means for evaluating behaviors. Because it does not rely on an external, independent observer it is easier to implement in real world settings. Unfortunately, self-assessment does not always accurately reflect the actual behavior in question (D. A. Davis et al., 2006). This may especially be the case if the individual performing the self-assessment does not have a clear understanding of the behavior they are being asked to report on, in this case patient-centered counseling. However, it is possible that if residents are instructed on patient-centered counseling, their ability to self-assess their own counseling skills, and their associated confidence in those skills, could improve over time. In fact, previous studies examining physician behavior suggest that training can improve the accuracy between observed behavior and self-report (Eva \& Regehr, 2005; Moret, Tequi, \& Lombrail, 2004). In general, perceived competence is a measure of the confidence one has to perform a certain task or behavior and has been associated with the actual performance of that behavior, including the ability to counsel (Eckstrom, Hickam, Lessler, \& Buchner, 1999; Lu \& Dollahite, 2010; Martin, Bruskiewitz, \& Chewning, 2010; Nikendei et al., 2011). Creation of a self-assessment tool to assess perceived competence for counseling could provide an efficient means for evaluating longitudinal evaluation of resident training in the area of patient-centered counseling, including for obesity.

\subsection{Purpose of the Research}

The objective of this study was to develop and validate a scale to assess residents' perceived-competence for patient-centered obesity counseling (PCOC). This work was done as a part of a larger effort to develop an obesity-counseling intervention tailored for residents (Burton et al., 2011). Development of this tool represents the first step in a body of work aimed at answering several research questions related to resident training:

(1) Does resident training in patient-centered counseling improve: (a) perceived competence in patient-centered counseling and (b) patient-centered counseling skills?

(2) Are improvements in perceived competence associated with improvements in counseling skills?

\section{Methods}

\subsection{Research Participants and Setting}

At a medical school in Alabama, resident physicians were invited to participate in a three-hour interactive obesity counseling workshop for resident physicians based on motivational interviewing (MI) techniques.

A convenience sample of 74 residents completed a pre- and post-intervention questionnaire to assess their knowledge, beliefs, and confidence (PCOC) in obesity counseling.

\subsection{Conceptual Framework and Item Generation of PCOC}

Candidate items were designed to assess perceived competence with regard to implementing the 5 A's, which served as the basis for our intervention: Assessing obesity risk and motivation to change; Advising lifestyle change; Agreeing with the patient on collaboratively set goals; Assisting in addressing barriers and resources; and Arranging for follow-up) (Jay et al., 2008; Jay et al., 2010; Serdula et al., 2003).

An important objective of our program was to help residents use a patient-centered approach to counseling. To that end, candidate items also reflect principles drawn from Motivational Interviewing. Motivational Interviewing emphasizes the 
patient's control and explores their ambivalence about change, and unlike traditional patient education it does not rely on the physician to provide often untailored advice to their patients (Miller \& Rollnick, 1991).

Initially, 2-3 items were developed to address perceived competencies associated with each of the 5 A's. This version of the scale was circulated to a multidisciplinary team of experts for review. The team included a nutritionist, two psychologists with expertise in Motivational Interviewing, a clinical weight-loss expert, and an expert in Health Education. Upon completion of this phase, the PCOC comprised of 3-5 items for each component (total items $=20$ ). Items were scored on a 5-point Likert scale with scores ranging from 5 (extremely confident) to 1 (not at all confident).

\subsection{Pilot Scale Testing}

The 20-item draft version of the PCOC was administered as part of a baseline assessment to a convenience sample of Internal Medicine and Pediatric residents at a medical school in Alabama who were participating in an obesity counseling workshop. Residents completed a baseline questionnaire that included brief demographics, the draft version of the PCOC, as well as a single-item measure of overall confidence in counseling, and a single item measuring outcome expectancy for obesity counseling ("Physicians can be effective in helping patients lose weight"). Appropriate permission was obtained from the leadership of both programs and the entire protocol was reviewed and approved by the institution's Institutional Review Board. All participants provided written informed consent.

\subsection{Statistical Analyses}

To explore the factor structure of the PCOC, we employed a principal component analysis (PCA) with Varimax rotation. An item was believed to load on a given factor if the factor loading was .50 or greater for that factor, and was less than .40 for each of the remaining two. The process was repeatedly applied, during which the cross-loading items were removed sequentially (Hatcher, 1994; Kim, 1978a, 1978b; Tabachnick, 2007). Coefficient alpha reliability estimates were subsequently calculated for each factor (Cronbach, 1951). As a preliminary assessment of criterion validity, total scores and subscale scores were correlated with a single-item measure of overall confidence in counseling and a single-item measure of outcome expectancy for obesity counseling. All analyses were conducted using SAS version 9.3 (S.I. Inc., 2012).

\section{Results}

\subsection{Sample Characteristics}

A convenience sample of 74 residents completed the questionnaire. (Table 1) Approximately half of the sample was female (57\%) and training in Internal Medicine (57\%). Residents were fairly evenly distributed across Post Graduate Year (PGY) level. Of note, the majority of residents plan to pursue a subspecialty.

\begin{tabular}{ll}
\hline Characteristic & Percent \\
\cline { 2 - 2 } Gender & \\
Female & 57.5 \\
Male & 42.7 \\
Track & 57.5 \\
Internal Medicine & 37.0 \\
Pediatrics & 5.5 \\
Med/Peds & \\
Training Year & 37.0 \\
PGY 1 & 27.4 \\
PGY 2 & 31.5 \\
PGY 3 & 2.7 \\
PGY 4 & \\
Career plans & 16.4 \\
Primary Care & 5.5 \\
Hospitalist & 60.3 \\
Subspecialty & 17.8 \\
Undecided &
\end{tabular}

Note: $P G Y=$ postgraduate year

The sample size of 74 on a 20-item questionnaire yielded a case per item ratio of 3.7 (MacCallum, Zhang, \& Hong S., 1999). A review of eigenvalues and the scree plot suggested a 3 -factor solution (Nunnally \& Berstein, 1994). Table 2 provides the factor structure for the scale. Eleven items were found to load on the first factor. Based on how item content related back to the 5A's, this factor was labeled Assist and Agree. Four items were found to load on the second factor, subsequently labeled Assess and Advise. Three items loaded on the third factor, subsequently labeled Arrange. Coefficient alpha reliability estimates for each factor are provided as parenthetical values in Table 2. 
Table 2. Factor structure of Perceived Competence for Obesity Counseling (PCOC) scale

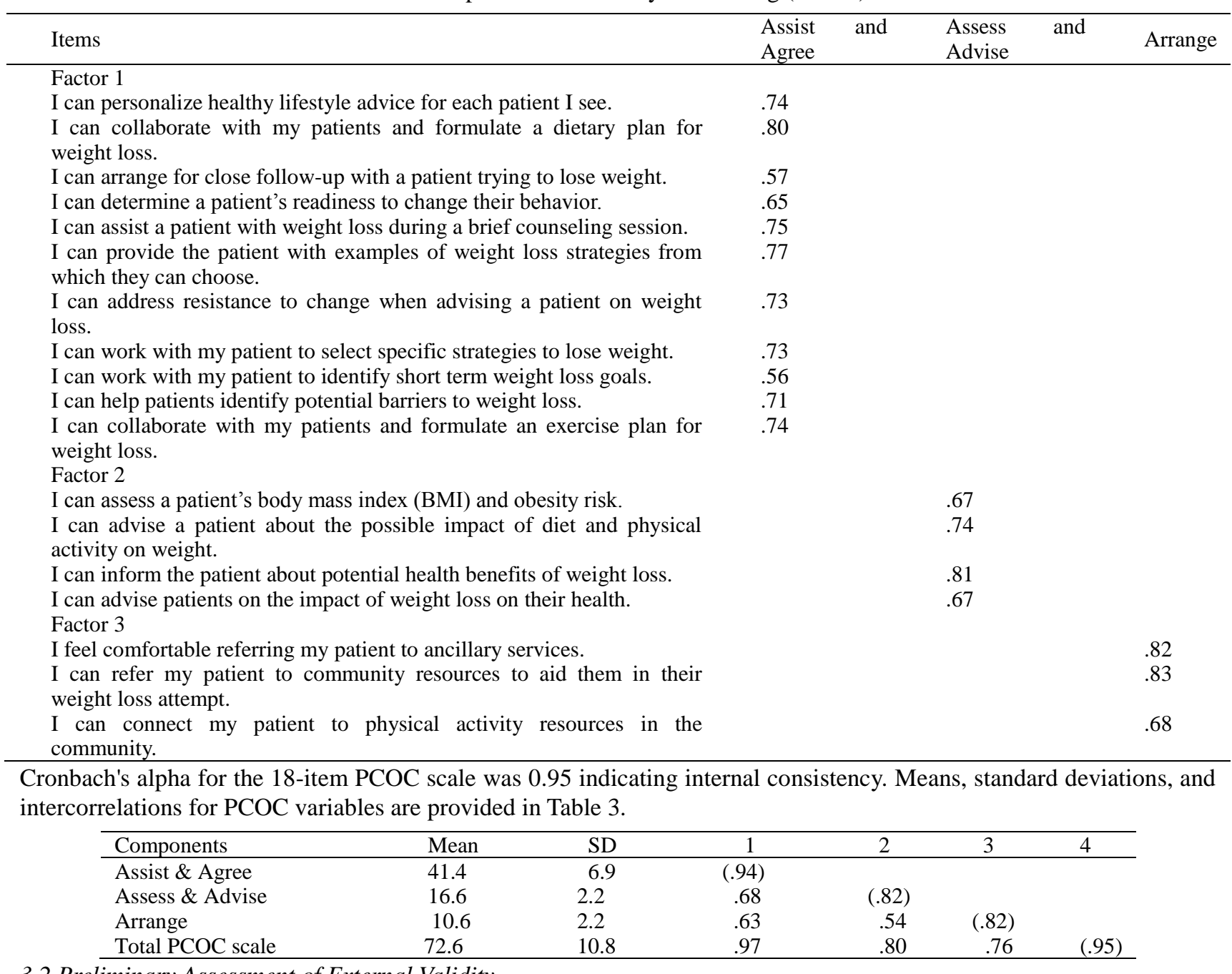

\subsection{Preliminary Assessment of External Validity}

Analyses revealed significant correlation between the PCOC Scale and a single-item measure of general confidence for obesity counseling as well a single-item measure of outcome expectancy for obesity counseling (Table 4).

Table 4. Correlations of physician confidence and outcome expectancy with all sub-scale and full-scale scores on the Perceived Competence for Obesity Counseling Scale (PCOC)

\begin{tabular}{llccc}
\hline \multicolumn{1}{c}{ Factor 1 } & Factor 2 & Factor 3 & PCOC \\
\hline $\begin{array}{l}\text { I feel well equipped to counsel my } \\
\text { patients about weight loss. }\end{array}$ & $.58^{* * *}$ & $.44^{* *}$ & $.51^{* *}$ & $.60^{* *}$ \\
$\begin{array}{l}\text { Primary Care physicians can be } \\
\text { effective in helping patients lose weight. }\end{array}$ & $.36^{* * *}$ & $.38^{* * *}$ & $.34^{* *}$ & $.41^{* *}$ \\
\hline
\end{tabular}

Note Factors: 1. Assist \& Agree, 2. Assess \& Advise, 3. Arrange, 4. PCOC scale; **p<.01

\section{Discussion and Implications}

\subsection{Validation of $P C O C$}

In this study, we developed an 18-item scale to assess residents' perceived competence for patient-centered obesity counseling. Analyses indicated a three-factor solution and a preliminary inspection of criterion validity suggested a relationship between scale results and general confidence in counseling and outcome expectancy related to obesity counseling. If future studies confirm these findings and demonstrate correlation with actual counseling skills, this measurement tool could be used to assess the effectiveness of programs designed to improve residents' confidence in counseling as part of a process to improve skills.

Perceived competence for an activity is thought to influence an individual's actual behavior or functioning because it helps determine selection of goals, persistence with regard to those goals, as well as problem solving around perceived 
barriers to selected goals (Larson \& Daniels, 1998). In the area of mental health, providers' perceived competence for counseling has been positively associated with counseling performance (Murdock, Wendler, \& Nilsson, 2005). Empirical evidence from professions including education and nursing suggest that individuals with higher perceived competence experience less burnout, increased job satisfaction and better job performance (Murdock et al., 2005). More recently, Perrin and colleagues used a single-item question on confidence for counseling and found that while physician confidence for counseling was low at baseline, training aimed at improving residents' obesity counseling skills increased confidence and frequency of weight-related counseling (Perrin et al., 2008).

The current study did not assess residents' confidence in counseling in relation to actual counseling skills. It is possible that programs aimed at improving residents counseling might improve perceived competence in counseling without qualitatively improving their actual skills. A recent meta-analysis reviewed the accuracy of physician self-assessment compared to observed measures of competence and found that physicians have a limited ability to accurately selfassess (David A. Davis et al., 2006); those who were the least skilled and those who were the most confident were the least accurate. However, the review goes on to suggest that training may reduce the discrepancy between observation and self-assessment by "encouraging the internalization of objective measurements or benchmarks of performance" (Eva \& Regehr, 2005). In the case of behavioral counseling, physicians' lack of training on patient-centered counseling may impede their ability to accurately self- assess their skills. If residents are taught the components of patient-centered counseling and given opportunities to practice those skills, their ability to self-assess may improve. If so, a tool such as PCOC could provide a proxy measure for counseling skills that is practical and efficient when compared to other evaluation methods such as direct observation or standardized patient interviews.

\subsection{Limitations and Strengths}

The data in the study come from a small sample of residents from a single site, limiting our ability to generalize. While the stability of factor loadings can be threatened with sample sizes below 200, previous investigators have found smaller subsamples $(n=78)$ sufficient to achieve factor solutions comparable to their full-factor solutions (Arirndell \& van der Ende, 1985). Nevertheless, future studies with a larger sample are needed in order to perform confirmatory analyses. Also, $65 \%$ of this sample planned to pursue a subspecialty or hospitalist career and as such many may not perceive as great a need for counseling.

Despite these limitations, there are strengths worth noting. First, the instrument we developed is brief, taking about 15 minutes to complete, which makes it easy to incorporate into residency training evaluation. Second, the tool has the potential to be adapted for counseling on other behaviors, such as smoking. This has been done successfully for similar tools that assess patients' perceived competence for health behaviors (Wallston, Rothman, \& Cherrington, 2007).

\subsection{Implications for Future Research}

Despite recommendations that physicians counsel their patients to lose weight, a minority of physicians regularly counsels their patients, citing lack of confidence in their skills as a significant barrier. As residency programs increasingly emphasize patient-centered counseling in order to improve physician skills and comply with ACGME core requirements, tools such as the one we developed will be useful for gauging the impact of teaching programs. Future studies are needed to assess the extent to which resident's perceived competence in patient-centered obesity counseling predicts actual performance in terms of both frequency and quality.

\section{Acknowledgments}

This work was made possible by grants from the University of Alabama Birmingham's Health Services Foundation Graduate Education Fund; the Robert Wood Johnson Physician Faculty Scholars' Program [047948], and the National Institutes of Health, National Institute of Diabetes and Digestive and Kidney Diseases, UAB Diabetes Research Center [1P60DK079626-01]. We would like to thank Kim Oswald, $\mathrm{PhD}$ and Heather Austin, $\mathrm{PhD}$ for their invaluable help in coding and scoring the qualitative data using MITI. We would also like to thank all our participants, Standardized Patients, support staff, and others who helped make this project possible.

\section{Conflict of Interest}

The authors have no conflict of interest to report. All authors have read this manuscript and given their permission for it to be published.

\section{References}

Accreditation Council for Graduate Medical Education. (2007). New Program Requirements. http://www.acgme.org/outcome/comp/compFull.asp

Arirndell, W., \& van der Ende, J. (1985). An empirical test of the utility of the obervation to variables ration in factor and components analysis. Applied Psychological Measurement, 9, 165-178. 
http://dx.doi.org/10.1177/014662168500900205

Burton, A. M., Agne, A. A., Lehr, S. M., Davis, N. J., Willett, L. L., \& Cherrington, A. L. (2011). Training residents in obesity counseling: incorporating principles of motivational interviewing to enhance patient centeredness. $J$. Grad. Med. Educ., 3(3), 408-411. http://dx.doi.org/10.4300/JGME-03-03-34

Colditz, G. A., Willett, W. C., Rotnitzky, A., \& Manson, J. E. (1995). Weight gain as a risk factor for clinical diabetes $\begin{array}{llllll}\text { mellitus in } \quad \text { women. } & \text { Intern }\end{array}$ http://dx.doi.org/10.7326/0003-4819-122-7-199504010-00001

Cronbach, L. J. (1951). Coefficient alpha and the internal construction of tests. Psycometrika, 16, $297-334$. http://dx.doi.org/10.1007/BF02310555

Davis, D. A., Mazmanian, P. E., Fordis, M., Van Harrison, R., Thorpe, K. E., \& Perrier, L. (2006). Accuracy of Physician Self-assessment Compared With Observed Measures of Competence: A Systematic Review. JAMA, 296(9), 1094-1102. http://dx.doi.org/10.1001/jama.296.9.1094

Eckstrom, E., Hickam, D. H., Lessler, D. S., \& Buchner, D. M. (1999). Changing physician practice of physical activity counseling. J. Gen. Intern. Med., 14(6), 376-378. http://dx.doi.org/10.1046/j.1525-1497.1999.00356.x

Eva, K. W., \& Regehr, G. (2005). Self-assessment in the health professions: a reformulation and research agenda. Acad. Med., 80(10 Suppl), S46-54. http://dx.doi.org/10.1097/00001888-200510001-00015

Flegal, K. M., Carroll, M. D., Ogden, C. L., \& Curtin, L. R. (2010). Prevalence and trends in obesity among US adults, 1999-2008, 303(3), 235-241. http://dx.doi.org/10.1001/jama.2009.2014

Forman-Hoffman, V., Little, A., \& Wahls, T. (2006). Barriers to obesity management: a pilot study of primary care clinicians. BMC Family Practice, 7(1), 35. http://dx.doi.org/10.1186/1471-2296-7-35

Glasgow, R. E., Emont, S., \& Miller, D. C. (2006). Assessing delivery of the five 'As' for patient-centered counseling. Health Promot. Int., 21(3), 245-255. http://dx.doi.org/10.1093/heapro/dal017

Goldstein, D. J. (1992). Beneficial health effects of modest weight loss. Int J Obes Relat Metab Disord, 16(6), $397-415$.

Hatcher, L. (1994). Step by Step Approach to Using the SAS System for Factor Analysis and Structural Equation Modeling. Cary: SAS Institute.

Huang, J., Yu, H., Marin, E., Brock, S., Carden, D., \& Davis, T. (2004). Physicians' Weight Loss Counseling in Two Public Hospital Primary Care Clinics. Academic Medicine, 79(2), 156-161. http://dx.doi.org/10.1097/00001888-200402000-00012

Jay, M., Gillespie, C., Ark, T., Richter, R., McMacken, M., Zabar, S., \& Kalet, A. (2008). Do internists, pediatricians, and psychiatrists feel competent in obesity care?: using a needs assessment to drive curriculum design. J. Gen. Intern. Med., 23(7), 1066-1070. http://dx.doi.org/10.1007/s11606-008-0519-y

Jay, M., Gillespie, C., Schlair, S., Sherman, S., \& Kalet, A. (2010). Physicians' use of the 5As in counseling obese patients: is the quality of counseling associated with patients' motivation and intention to lose weight? BMC Health Serv Res, 10, 159.

Kim, J. O. M. C. W. (1978a). Introduction to factor analysis: What is it and how to do it. Beverly Hills: Sage.

Kim, J. O. M. C. W. (1978b). Factor analysis: Statistical methods and practical issues. Beverly Hills: Sage.

Kushner, R. F. (1995). Barriers to providing nutrition counseling by physicians: a survey of primary care practitioners. Prev. Med., 24(6), 546-552. http://dx.doi.org/10.1006/pmed.1995.1087

Larson, L. M., \& Daniels, J. A. (1998). Review of the Counseling Self-Efficacy Literature. The Counseling Psychologist, 26(2), 179-218. http://dx.doi.org/10.1177/0011000098262001

Loureiro, M. L., \& Nayga, R. M., Jr. (2006). Obesity, weight loss, and physician's advice. Soc. Sci. Med., 62(10), 2458-2468. http://dx.doi.org/10.1016/j.socscimed.2005.11.011

Lu, A. H., \& Dollahite, J. (2010). Assessment of dietitians' nutrition counselling self-efficacy and its positive relationship with reported skill usage. J. Hum. Nutr. Diet., 23(2), 144-153. http://dx.doi.org/10.1111/j.1365-277X.2009.01024.X

MacCallum, R., Zhang, K., \& Hong S., S. (1999). Sample size in factor analysis. Psychological Methods, 4(1), 84-99. http://dx.doi.org/10.1037/1082-989X.4.1.84

Martin, B. A., Bruskiewitz, R. H., \& Chewning, B. A. (2010). Effect of a tobacco cessation continuing professional education program on pharmacists' confidence, skills, and practice-change behaviors. J. Am. Pharm. Assoc. (2003), 
50(1), 9-16. http://dx.doi.org/10.1331/JAPhA.2010.09034

McTigue, K. M., Harris, R., Hemphill, B., Lux, L., Sutton, S., Bunton, A. J., \& Lohr, K. N. (2003). Screening and interventions for obesity in adults: summary of the evidence for the U.S. Preventive Services Task Force. Ann. Intern. Med., 139(11), 933-949.

Miller, W. R., \& Rollnick, S. (1991). Motivational interviewing: Preparing people to change addictive behavior. New York: Guilford Press.

Moret, L., Tequi, B., \& Lombrail, P. (2004). Should self-assessment methods be used to measure compliance with handwashing recommendations? A study carried out in a French university hospital. Am. J. Infect. Control, 32(7), 384-390.

Murdock, T. B., Wendler, A. M., \& Nilsson, J. E. (2005). Addiction counseling self-efficacy scale (ACSES): development and initial validation. J. Subst .Abuse. Treat., 29(1), 55-64. http://dx.doi.org/10.1016/j.jsat.2005.03.005

Nikendei, C., Bosse, H. M., Hoffmann, K., Moltner, A., Hancke, R., Conrad, C., \& Schultz, J. H. (2011). Outcome of parent-physician communication skills training for pediatric residents. Patient Educ. Couns., 82(1), 94-99. http://dx.doi.org/10.1016/j.pec.2009.12.013

Nunnally, J., \& Berstein, I. (1994). Psychometric Theory. New York: McGraw-Hill.

Perrin, E. M., Vann, J. C. J., Lazorick, S., Ammerman, A., Teplin, S., Flower, K., \& Benjamin, J. T. (2008). Bolstering confidence in obesity prevention and treatment counseling for resident and community pediatricians. Patient Education and Counseling, 73(2), 179-185. http://dx.doi.org/10.1016/j.pec.2008.07.025

Rosal, M. C., Ebbeling, C. B., Lofgren, I., Ockene, J. K., Ockene, I. S., \& Hebert, J. R. (2001). Facilitating dietary change: the patient-centered counseling model. J. Am. Diet. Assoc., 101(3), 332-341. http://dx.doi.org/10.1016/S0002-8223(01)00086-4

S.I. Inc. (2012). SAS 9.3. Cary, NC.

Serdula, M. K., Khan, L. K., \& Dietz, W. H. (2003). Weight loss counseling revisited. JAMA, 289(14), 1747-1750. http://dx.doi.org/10.1001/jama.289.14.1747

Sherwin, R. S., Anderson, R. M., Buse, J. B., Chin, M. H., Eddy, D., Fradkin, J., \& Zinman, B. (2004). Prevention or delay of type 2 diabetes. Diabetes Care, 27(Suppl 1), S47-54. http://dx.doi.org/10.2337/diacare.27.2007.S47

Stafford, R. S., Farhat, J. H., Misra, B., \& Schoenfeld, D. A. (2000). National Patterns of Physician Activities Related to Obesity Management. Arch. Fam. Med., 9(7), 631-638. http://dx.doi.org/10.1001/archfami.9.7.631

Swinburn, B., Sacks, G., Hall, K., McPherson, K., Finegood, D., Moodie, M., \& Gortmaker, S. (2011). The global obesity pandemic: Shaped by global drivers and local environments. Lancet, 378(9793), 804-814. http://dx.doi.org/10.1016/S0140-6736(11)60813-1

Tabachnick, B. G. F., L.S. (2007). Using Multivariate Statistics. (5th ed.). Boston: Pearson, Allyn and Bacon.

Walker, S., Rimm, E., Ascherio, A., Kawachi, I., Stampfer, M., \& Willett, W. (1996). Body size and fat distribution as predictors of stroke among US men. Am. J. Epidemiol., 144(12), 1143-1150. http://dx.doi.org/10.1093/oxfordjournals.aje.a008892

Wallston, K. A., Rothman, R. L., \& Cherrington, A. (2007). Psychometric properties of the Perceived Diabetes Self-Management Scale (PDSMS). J. Behav. Med., 30(5), 395-401. http://dx.doi.org/10.1007/s10865-007-9110-y

Whitlock, E. P., Orleans, C. T., Pender, N., \& Allan, J. (2002). Evaluating primary care behavioral counseling interventions: an evidence-based approach. Am. J. Prev. Med., 22(4), $267-284$. http://dx.doi.org/10.1016/S0749-3797(02)00415-4

\section{$(\mathrm{cc}) \mathrm{BY}$}

This work is licensed under a Creative Commons Attribution 3.0 License. 